\section{Effect of physical activity on cartilage development in healthy kids}

\section{G Jones, K Bennell, F M Cicuttini}

\section{Current evidence supports a prescription of vigorous physical activity for optimum joint development in children}

$\mathrm{P}$ hysical activity in childhood has many health benefits. In the musculoskeletal area, physical activity leads to substantial gains in bone mass, at least some of which are maintained into later life. ${ }^{1}$ The most opportune time for intervention appears to be the prepubertal and early pubertal years. ${ }^{1-4}$ However, much less is known about joint development. Recently, advances in magnetic resonance imaging have allowed an accurate in vivo assessment of hyaline cartilage in joints. Most studies have been of the knee, but methods for hip and hand assessment have also been validated. Magnetic resonance imaging is accurate and highly reproducible with coefficients of variation of $2-3 \% .^{56}$

Development of articular hyaline cartilage in the knee appears to be a very dynamic process. ${ }^{6}$ Physical activity has been shown to be associated with cartilage development both cross sectionally and longitudinally in randomly selected healthy children without knee pain or injury. ${ }^{56}$ Cross sectionally, physical activity was a significant explanatory factor for cartilage volume at all knee sites $\left(R^{2}\right.$ $7-14 \%){ }^{5}$ The most striking association was with vigorous activity in the last two weeks: children with no vigorous activity had volumes $22-25 \%$ less than even mildly active children. There were also less consistent associations with number of sports and type of sports (particularly cross training) but not light exercise. In contrast, a smaller cross sectional study of adult triathletes found no difference in cartilage volume or size with exercise, although bone size was generally larger in triathletes. ${ }^{7}$ This raises the question of whether physical activity may have a differential effect on joint cartilage with age.

$$
\begin{aligned}
& \text { "... withholding exercise in early } \\
& \text { life may result in delayed } \\
& \text { adaptation of the cartilage." }
\end{aligned}
$$

When followed longitudinally, most children gained cartilage and only a minority lost cartilage over a 1.6 year time frame. ${ }^{6}$ The average increase was $7-15 \%$ per annum in boys and $4-10 \%$ per annum in girls (depending on the site within the knee). Cartilage volume accrual correlated with height change at medial and lateral tibial sites $(\mathrm{p}=0.001)$ but not at the patellar sites. Physical activity associations again appeared important. The most consistent physical activity association with gain in joint cartilage was with average intensity of sport. Those with average intensity of sport above the median gained approximately twice as much as those below the median at the tibial but not patella sites. Less consistent associations were also observed for vigorous activity within the last two weeks. The wide range in cartilage acquisition (particularly in the prepubertal and early pubertal years) suggests that it may be amenable to environmental modification. Taken as a whole, the cross sectional and longitudinal studies suggest that vigorous activity during childhood promotes development of knee cartilage in the absence of significant injury and/or pain.

We can then turn to in vitro and animal studies to try to understand the effect of mechanical loading on cartilage development. There is well established evidence that mechanical stimuli can influence articular chondrocyte shape and stimulate alterations in cellular biochemistry and matrix metabolism. ${ }^{8}$ Mechanical forces affect chondrocyte biosynthesis and gene expression. ${ }^{9}$ In vitro, cyclic mechanical compression resulted in about twice as many mesenchymal cells being induced to enter the chondrogenic pathway. The coincidence of the increase in sulfate incorporation and nodule density suggested that the primary effect of mechanical compression on mesenchymal cells is on cellular differentiation and not on their subsequent metabolism. ${ }^{9}$ A further study also showed that functional adaptation of articular cartilage, as reflected in the formation of biochemical heterogeneity in the horse, occurs for the most part during the first five months post partum. ${ }^{10}$ This suggested that a certain level of exercise seems to be essential for this process, and withholding exercise in early life may result in delayed adaptation of the cartilage. studies that suggest that lack of physical activity adversely affects articular cartilage development. Newborn foals that
There are very good data from animal had lack of exercise-that is, were box rested-were shown to be retarded in development of joint cartilage. ${ }^{11}$ This delay in development of articular cartilage was not compensated for when box confinement was lifted after five months. ${ }^{12}$ In rats, elimination of weight bearing was associated with cartilage thinning. ${ }^{13}$ Animal studies suggest that mechanical forces also influence the synthesis and rate of turnover of articular cartilage molecules, such as proteoglycans. $^{14}$

It is thus possible that articular cartilage in humans responds to physical activity in a similar manner to bone. Although bone density is largely genetically determined, recent research has highlighted the importance of exercise during growth to maximise the attainment of peak bone density. Greater peak bone density may then reduce the risk of osteoporotic fracture in later life. Similarly, greater cartilage volume attained in the growing years with physical activity may reduce the risk of developing knee osteoarthritis, particularly given that cartilage loss is the hallmark of osteoarthritis, Furthermore, we observed sex and site differences in cartilage development, ${ }^{5}$ which parallel the largely unexplained variations in osteoarthritis incidence in later life.

"The current evidence supports a
prescription of vigorous physical
activity for optimum joint
development in children."

There are a number of limitations to the currently available human studies. The wide age range studied makes it difficult to sort out whether the physical activity effect was independent of age, as younger children had both greater cartilage acquisition and higher activity levels. Secondly, measurement of physical activity in children is difficult, and questionnaires have a number of well recognised problems. Ideally, further studies will need to be of a longitudinal design, examine children of a similar age, and objectively measure physical activity. Nevertheless, the current evidence supports a prescription of vigorous physical activity for optimum joint development in children.

Br J Sports Med 2003;37:382-383

\section{Authors' affiliations}

G Jones, Menzies Centre for Population Health Research

K Bennell, University of Melbourne

F M Cicuttini, Monash University, Melbourne, Australia

Correspondence to: Associate Professor Cicuttini, 3rd Floor, 553 St Kilda Rd, Melbourne, Vic 3001, Australia:

flavia.cicuttini@med.monash.edu.au 


\section{REFERENCES}

1 Bass S, Pearce G, Bradney M, et al. Exercise before puberty may confer residual benefits in bone density in adulthood: studies in active prepubertal and retired female gymnasts. J Bone Miner Res 1998;13:500-7.

2 Jones G, Dwyer T. Bone mass in prepubertal children: gender differences and the role of physical activity and sunlight exposure. J Clin Endocrinol Metab 1998;83:4274-9.

3 Bradney M, Pearce G, Naughton G, et al. Moderate exercise during growth in prepubertal boys: changes in bone mass, size volumetric density, and bone strength: a controlled prospective study. J Bone Miner Res 1998;13:1814-21.

4 MacKelvie K, McKay HA, Khan KM, et al. Defining the window of opportunity: a school-based loading intervention augments bone mineral accrual in early pubertal girls. $J$ Pediatr 2001:139:501-7.
5 Jones G, Glisson M, Hynes K, et al. Sex and site differences in cartilage development: a possible explanation for variations in knee osteoarthritis in later life. Arthritis Rheum 2000:43:2543-9

6 Jones G, Ding C-H, Hynes KL, et al. Knee articular cartilage development in children: a longitudinal study of the effect of gender, growth, Tanner stage and physical activity. Pediatr Res 2003; in press

7 Eckstein F, Faber S, Muhlbauer R, et al. Functional adaptation of human joints to mechanical stimuli. Osteoarthritis Cartilage 2002; 10:44-50.

8 Hung SC, Nakamura K, Shiro R, et al. Effects of continuous distraction on cartilage in a moving joint: an investigation on adult rabbits. J Orthop Res 1997;15:381-90.

9 Elder SH, Kimura JH, Soslowsky L, et al. Effect of compressive loading on chondrocyte differentiation in agarose cultures of chick limb-bud cells. J Orthop Res 2000;18:78-86.
10 Brama PA, TeKoppele JM, Bank RA, et al. Development of biochemical heterogeneity of articular cartilage: influences of age and exercise. Equine Vet J 2002;34:265-9.

11 van den Hoogen $B M$, van den Lest $\mathrm{CH}$, van Weeren PR, et al. Effect of exercise on the proteoglycan metabolism of articular cartilage in growing foals. Equine Vet J Suppl 1999;31:62-6.

12 Barneveld A, van Weeren PR. Early changes in the distal intertarsal joint of Dutch warm blood foals and the influence of exercise on bone density in the third tarsal bone. Equine Vet J Suppl 1999:31:67-73.

13 O'Connor KM. Unweighting accelerates tidemark advancement in articular cartilage at the knee joint of rats. J Bone Miner Res $1997 ; 12: 580-9$

14 Wei L, Svensson O, Hierpe A. Correlation of morphologic and biochemical changes in the natural history of spontaneous osteoarthrosis in guinea pigs. Arthritis Rheum 1997;40:2075-83.

2003 AUSTRALIAN CONFERENCE OF SCIENCE AND MEDICINE IN SPORT AND THIRD NATIONAL SPORTS INJURY PREVENTION CONFERENCE

"Tackling the Barriers to Participation and Performance"

25-28 October 2003 National Convention Centre, Canberra, Australia

\section{THE VIKINGS ARE COMING!}

\section{- Professor Roald Bahr, Oslo, Norway}

Chair of the Oslo Sports Trauma Research Centre the University of Sport and Physical Education in Norway. Professor Bahr is also a consultant physician at the Department of Sports Medicine, in the Norwegian National Sports Centre. He is acknowledged as one of the world's leading authorities on the causes and prevention of sporting injury.

\section{- Dr Hakan Alfredson, Umea, Sweden}

An orthopaedic surgeon from the University Hospital Umea, in Sweden. Sports physiotherapists in particular have been trying for some time to get Professor Alfredson to Australia. He is an authority on the treatment of tendon injuries and on articular cartilage repair and surgery, specifically patella femoral articular cartilage and perosteal grafts.

- Professor Stephan Rossner, Stockholm, Sweden

Director, Obesity Research Program, Luddinge Hospital, Stockholm, Sweden and Past President of the International Association for the Study of Obesity (IASSO).

The Vikings will be backed up by a Longboat crew of local and international luminaries including Bartold, Best, Cardwell, Chan, Cook, Cross, Fiatarone Singh, Gilbey, Hart, Linklater, Lucas, Mummery, Norton, Purdham, Sando, Selig, Steele, Sullivan, Terry, and Tipton.

Programme highlights

- Sir William Refshauge Lecture by Dr Brian Sando, former Australian Olympic Team Chief Doctor

- "How to Give Medical Evidence in Court". A hands on workshop in a real courtroom

- Professor Maria Fiatarone Singh: Exercise in older adults-are the barriers real or imagined?

- Dr John Best, Australian Rugby Union Chief Medical Officer: Injury and rugby issues

- Cardiac barriers to participation: Exercise, prevention, and rehabilitation

- Professor Kevin Norton: Intervention strategies for increasing physical activity patterns

- Dr Craig Purdham and Dr Jill Cook: New Views on Tendons

- Hypothetical "The fat Australian: Who's to Blame?" chaired by Dr Glenn Cardwell

- Debate: Is 30 minutes of physical activity a day sufficient for Health Benefit? Chaired by Prof Wendy Brown.

Plus the opportunity to attend the Wales versus Italy World Cup Rugby Union match.

\section{Call for Papers}

The conference Committee is calling for abstracts for podium and poster presentations. Researchers are also invited to join with colleagues to submit a group of three or more abstracts which focus on any aspect of the Conference theme, to be presented in a single "symposium" session.

All accepted abstracts will be published in a supplement to the Journal of Science and Medicine in Sport.

All submitted papers are eligible for more than A\$28,000 in prize money as part of the Australian Sports Medicine Federation Fellows' Awards.

$$
\begin{aligned}
& \text { Please see www.sma.org.au/2003conference/call_for_papers for further details } \\
& \text { www.sma.org.au • email: sma.conf@sma.org.au • tel: +61 } 262304650
\end{aligned}
$$

